\title{
Returning to school after a terror attack: a longitudinal study of school functioning and health in terror-exposed youth
}

\author{
Lise Eilin Stene ${ }^{1} \mathbb{D} \cdot$ Jon-Håkon Schultz ${ }^{2} \cdot$ Grete Dyb $^{1,3}$
}

Received: 22 January 2018 / Accepted: 18 June 2018 / Published online: 12 July 2018

(c) The Author(s) 2018

\begin{abstract}
Terrorist attacks and mass shootings often involve youth. Knowledge is needed on how this may impact their health and functioning. This study investigates perceived academic performance and school wellbeing in 237 terror-exposed survivors of the Utøya youth camp attack according to their sociodemographic characteristics, health and mental health service (MHS) utilization. Semi-structured interviews were conducted after 4-5 and 14-15 months. The year following the attack, 143 (61\%) survivors reported impaired academic performance and 66 (29\%) impaired school wellbeing. Female survivors more often reported impaired performance. Non-Norwegian origin, being financially disadvantaged and less social support were associated with impaired wellbeing. Sleep problems, posttraumatic stress, anxiety/depression, somatic symptoms, and lower life satisfaction were associated with both impaired performance and impaired wellbeing. Survivors who had received MHS were more likely to report impaired or improved academic performance and school wellbeing. Higher age and posttraumatic stress reactions were associated with impaired academic performance after multivariate logistic regression adjustments for gender, somatic symptoms and social support. When additionally adjusting for impaired school wellbeing, age and impaired wellbeing were associated with impaired performance. Only posttraumatic stress reactions were associated with impaired wellbeing after similar adjustments. Non-Norwegian origin and being financially disadvantaged were not significantly associated with impaired wellbeing after adjusting for posttraumatic stress reactions, age and gender. Our findings demonstrate how a terrorist attack can considerably deteriorate young survivors' performance and wellbeing at school, which is associated with poorer health. Consequently, it is important to provide appropriate school support, and coordinate MHS with follow-up at school.
\end{abstract}

Keywords Stress disorders · Posttraumatic $\cdot$ Terrorism $\cdot$ Academic performance $\cdot$ Adolescent $\cdot$ Young adult $\cdot$ Quality of life $\cdot$ Public health $\cdot$ Social support $\cdot$ Education $\cdot$ Mental health services

Electronic supplementary material The online version of this article (https://doi.org/10.1007/s00787-018-1196-y) contains supplementary material, which is available to authorized users.

Lise Eilin Stene

lise.stene@nkvts.no

1 Norwegian Centre for Violence and Traumatic Stress Studies, NKVTS, Oslo, Norway

2 Department of Education, University of Troms $\varnothing$, The Arctic University of Norway, Troms $\emptyset$, Norway

3 Institute of Clinical Medicine, Faculty of Medicine, University of Oslo, Oslo, Norway

\section{Introduction}

Terrorist attacks and shooting sprees often involve adolescents and young adults. Trauma exposure may be particularly detrimental in the transition from adolescence to adulthood as it may perturb the young survivor's psychosocial development and education with potential long-term adversity, including chronic mental disorders and disability at school and work [1,2]. Traumatic experiences may activate posttraumatic stress responses that disturb sleep, concentration and cognition, and consequently undermine the school functioning [3-8]. Injuries and somatic symptoms, such as chronic pain and fatigue, might further impair concentration and lead to absence from school [9]. A supportive school environment may be an important source of social support, which is considered among the most protective factors against posttraumatic mental health problems [10]. 
Conversely, negative reactions from social surroundings augment the risk of mental health problems [11]. Establishing effective preventative measures is especially important in youth as it may prevent many years lost to disability [12]. Schools and educational institutions may play a crucial role in the follow-up of youth exposed to traumatic events. These are places where deterioration of health and functioning can potentially be uncovered and prevented, and interventions implemented [13]. Although terror attacks and mass shootings frequently affect school pupils and students, little is known about their academic performance and their wellbeing at school after such events. To strengthen educational institutions' and health care services' responses to mass casualties, and prevent long-term disability and marginalization, knowledge is needed about the relationship between young survivors' school functioning, posttraumatic health and mental health service utilization.

This study examined how youth perceived their school functioning the year following exposure to a terrorist attack. On July 22, 2011, a solitary extreme right perpetrator carried out two attacks in Norway. After detonating a bomb in the Oslo Government Quarter, he executed a shooting massacre at the summer camp of a political youth organization on the Utøya island. During the 1.5-h-long shooting, 69 persons were killed, and many were injured or risked drowning while trying to escape by swimming. The Utøya shooting is considered a severe trauma because of the high number of fatalities and physically injured, that many lost close ones, the young age of those involved and the fact that they were designated targets.

The survivors were mostly students in upper secondary school or higher education programs. The school semester started 4 weeks after the massacre, and the Norwegian Ministry of Education instructed the schools to contact all students to plan their return to school and to tailor possible adaptations throughout the school year [14, 15]. In addition, detailed information was posted on the Ministry's website about pupils' rights to educational adaptations, including information from the Norwegian Education Act (2006) on permitted absence and alternative ways of assigning grades and completing classes in high school when the student's absence is high $[2,16]$. Teachers and school health workers were asked to be proactive and provide survivors with close follow-ups, supporting them to complete their school program. The importance for the school to work together with health professionals was frequently mentioned in the Ministry's communication.

The aim of this study was to generate knowledge to improve educational institutions' and health care services' support for young survivors of terror attacks and other mass traumas, and prevent impairments in their school functioning and health. Our specific objectives were to (a) examine the perceived academic performance and school wellbeing in youth exposed to mass trauma and their need for school support, and (b) investigate their perceived school functioning according to their sociodemographic characteristics, health status and specialized mental health service utilization.

\section{Methods}

\section{Participants and procedures}

This study includes data from two survey waves of the survivors of the Utøya attack. Overall, 495 survivors who had been on the Utøya island during the shooting were identified from police records. The recruitment consisted of three stages: (1) a postal invitation, (2) a telephone call, and (3) an interview with those who answered the call and agreed to participate. Four survivors aged $\leq 13$ years and one who lived abroad were excluded, hence postal study invitations were sent to 490 survivors. Semi-structured face-to-face interviews were performed at 4-5 months (wave 1) and 14-15 months (wave 2) after the attack. The study had an open cohort design in which all of the eligible survivors were invited to participate at both waves. Overall, 325 (66\%) of the survivors participated at wave 1, and $285(58 \%)$ at wave 2 [17]. At the second survey wave, there was a set of questions exclusively for survivors who were school pupils or students during the school year following the shooting (2011/2012). In total, 237 survivors answered at least one of these questions and were included in this study.

\section{Variables}

School functioning was assessed at both waves by two questions concerning (1) the survivors' perceived academic performance, and (2) their wellbeing at school. At wave 1 they were asked during the interview, and at wave 2 in a questionnaire filled out directly after the interview, with the interviewer available in case of questions. At wave 2, survivors were asked if they had been school pupils or students during the school year following the shooting (2011/2012). Those who answered yes were asked if they completed the year (yes/no), if their academic performance or wellbeing at school/studies had changed (two separate questions with three response alternatives: worse/unchanged/better), and if they had received auxiliary school support (yes/no) after the shooting. In the analyses, the response alternatives "unchanged" and "better" were merged into one category (not impaired). Furthermore, they were asked whether they had needed practical facilitations (e.g. adjournments of test/exams), auxiliary academic assistance from teachers, additional social or emotional support, and how satisfied they were with school support. These four questions had five response 
alternatives: (a) not at all, (b) to a small extent, (c) to some extent, (d) to a large extent, and (e) to a very large extent. The alternatives were collapsed into three categories: no/ little $(\mathrm{a}+\mathrm{b})$, some $(\mathrm{c})$, and much/very much $(\mathrm{d}+\mathrm{e})$.

Mental health service (MHS) utilization (yes/no) was assessed at wave 1 (covered contact with mental health services approximately $0-5$ months after the attack) and wave 2 (covered contact from January 1, 2012 until interview at wave 2, i.e., approximately 5-15 months after the attack). Predisaster MHS utilization was assessed at wave 2 by a question on whether they had received MHS before the terror attack.

Posttraumatic stress reactions in the past month were measured by the University of California at Los Angeles PTSD Reaction Index (UCLA PTSD-RI) [18]. The total score covers 17 items that correspond to the 17 PTSD DSM-IV symptoms rated on a 5-point Likert scale from $0=$ never to $4=$ most of the time. Three items have two alternative formulations where the item with the highest score is included. Reactions experienced "much of the time" and "most of the time" were defined as clinical symptoms. Cronbach's alpha was 0.89 both at wave 1 and 2 .

Symptoms of depression and anxiety were assessed with Hopkins Symptom Checklist-8 (SCL-8). It comprises eight items scored from 1 (not bothered) to 4 (very much bothered) which cover symptoms of depression and anxiety the past 2 weeks $[19,20]$. Cronbach's alpha was 0.85 at wave 1 and 0.89 at wave 2 . Somatic symptoms the preceding 2 weeks were assessed by a short eight-item version of Children's Somatic Symptoms Inventory (CSSI-8) [21]. It covers pain in stomach, head, lower back, and arms/legs, faintness/dizziness, rapid heartbeat, nausea/stomach problems, and weakness. Each item is scored from 1 (not bothered) to 4 (very much bothered). Cronbach's alpha was 0.77 at wave 1 and 0.75 at wave 2 . Social support was measured by seven items scored from 1 (much less than I would like) to 5 (as much as I would like) from the Duke-University of North Carolina Functional Social Support Questionnaire (FSSQ) [22]. Cronbach's alpha was 0.80 at wave 1 and 0.85 at wave 2 . Sleep problems were assessed by a question from the UCLA PTSD-RI on how often during the past month they had trouble going to sleep or waking up often during the night using five response alternatives. Survivors who answered twice a week or more were classified as having sleep problems. Terror exposure was assessed at wave 1 by a sum score of 13 potentially traumatic events occurring during the attack, which has been shown to be independently associated with mental health problems [23]. Participants at wave 2 who did not participate at wave 1 answered questions on terror exposure in wave 2. Life satisfaction was evaluated at wave 2 by the question "How satisfied are you with your life, in general?" scored from a scale from 1 (very dissatisfied) to 10 (very satisfied).
Financial status was evaluated by asking survivors how they perceived their parents' (survivors who lived with their parents) or their own (survivors who did not live with their parents) economy compared to others. It was evaluated at wave 1 except for participants who joined the study at wave 2. In the latter case, the financial status was evaluated at wave 2 . The five response alternatives were dichotomized into financially disadvantaged (much or somewhat poorer) or not (similar, somewhat better, and much better).

Age was assessed at the time of the attack as a continuous variable with one decimal. Furthermore, non-Norwegian origin was defined as having both parents born abroad.

\section{Ethics}

The study participation was based on written informed consent. Parental consent was required for survivors younger than 16 years of age, as stipulated by Norwegian laws. The interviewers had a health-related background and were trained in conducting research interviews with traumatized individuals at a seminary before the study. They worked in teams of two, and after each wave there was a seminary where they could share experiences. The interviewers were instructed to assist survivors in contacting suitable services if they identified survivors with unmet help needs. A phone line was provided for the interviewers where they could receive support. The study was approved by the Regional Committees for Medical and Health Research Ethics South East and North.

\section{Statistical analysis}

In the bivariate analyses, Pearson Chi-square tests were used for categorical variables, and independent $t$ tests for continuous variables. Our level of statistical significance was $p<0.05$. The two dependent variables; academic performance and school wellbeing at 14-15 months after the attack (wave 2), were dichotomised into impaired or not by merging the response categories "unchanged" and "better" into "not impaired". Due to sample strength considerations (statistical power), we limited the number of degrees of freedom to five in our multivariable analyses. We did an à priori selection of the following independent variables: age, gender, and posttraumatic stress reactions; somatic symptoms; and social support measured 4-5 months after the attack (wave 1). Furthermore, we did a post hoc analysis to examine whether non-Norwegian origin and being financially disadvantaged would remain significantly associated with impaired school wellbeing after adjustments for age, gender and posttraumatic stress reactions. The percentages were calculated from the total number of responses for the respective variables, and the analyses were based on the total number of answers. We lacked wave 1 data from 26 survivors who participated 
at wave 2 only. Otherwise, there was little missing data. No respondents had more than two items with missing values in any of the scales (PTSD-RI, SCL-8, CSSI-8 and FSSQ7). The mean scores of the answered items were used in the analyses. The crude and adjusted odds ratios (ORs) were presented with $95 \%$ confidence intervals $(\mathrm{CI})$. The analyses were effectuated with IBM SPSS version 24.

\section{Results}

The median age of the student participants at the time of the attack was 17, 3 years (range 13.3-33.8 years, 95\% were 23.1 years or younger), 113/237 (48\%) were female, and 19/233 (8\%) were of non-Norwegian origin. The characteristics of terror exposure among the participants are described in Table 1. At 4-5 months after the attack (wave 1), 135 (69\%) survivors perceived their academic performance to be impaired, 44 (23\%) to be unchanged and 16 (8\%) to be improved compared to before the attack. Next, 14-15 months after the attack (wave 2), 143 (61\%) survivors reported their academic performance to be impaired, $61(26 \%)$ to be unchanged, and $29(12 \%)$ to be improved (Fig. 1). Among survivors who disclosed impaired academic performance at wave 1, 100 also did so at wave 2; whereas 19 reported unchanged, and 15 improved academic performance. With respect to impaired school wellbeing, 58 (30\%) survivors disclosed impaired, 51 (26\%) improved, and 85 (44\%) no changes in wellbeing 4-5 months after the attack; whereas 66 (29\%) survivors disclosed impaired, 49 (21\%)

Table 1 Characteristics of exposure in the sample of student survivors of the Utøya attack

\begin{tabular}{lc}
\hline Exposure characteristics & $n(\%)$ \\
\hline Saw the terrorist or heard his voice, $n=232$ & $164(70.7)$ \\
Hid from or ran from the terrorist, $n=232$ & $226(97.4)$ \\
Heard gun shots & $233(100)$ \\
Heard people screaming, $n=231$ & $215(93.1)$ \\
Smelled gunfire or other distinct smells, $n=228$ & $74(32.5)$ \\
Saw someone be injured or killed, $n=231$ & $147(63.6)$ \\
Heard someone be injured or killed, $n=230$ & $184(80.0)$ \\
Saw dead bodies, $n=231$ & $198(85.7)$ \\
Touched dead bodies or injured people, $n=232$ & $102(44.0)$ \\
Was afraid of being seriously injured, $n=231$ & $174(75.3)$ \\
Was afraid that he/she would die, $n=231$ & $181(78.4)$ \\
Saw the terrorist point the gun at him/her or realized & $100(42.9)$ \\
that he had shot at him/her, $n=233$ & \\
Was afraid that he/she would drown, $n=232$ & $67(28.9)$ \\
Felt threatened by the police, $n=227$ & $93(41.0)$ \\
\hline
\end{tabular}

All survivors $(100 \%)$ heard gun shots; hence a sum of exposure (0-13) was calculated from all characteristics except "heard gun shots"

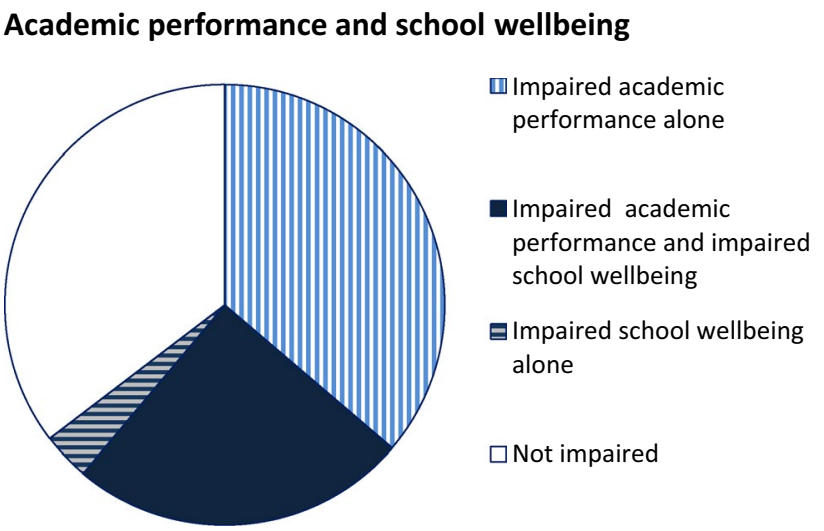

Fig. 1 Overall 229 survivors of the Utøya attack answered both questions on academic performance and school wellbeing 14-15 months after the attack, including 57 (25\%) who reported both impaired academic performance and impaired school wellbeing, $83(36 \%)$ impaired performance alone, 8 (4\%) impaired wellbeing alone, and $81(35 \%)$ neither impaired performance nor impaired wellbeing

improved, and 116 (50\%) reported no changes in wellbeing 14-15 months after the attack. Of those who reported impaired wellbeing at wave 1,33 also did so at wave 2, whereas 19 of them reported unchanged and 5 improved wellbeing at wave 2. Overall, 61 (26\%) reported that they did not complete the study year. In the bivariate analyses, impaired academic performance reported 14-15 months after the attack was associated with female gender; sleep problems; symptoms of posttraumatic stress, anxiety and depression; somatic symptoms; lower life satisfaction, and not completing the study year (Table 2). Impaired wellbeing was associated with non-Norwegian origin; being financially disadvantaged; sleep problems; symptoms of posttraumatic stress, anxiety and depression; somatic symptoms; less social support; lower life satisfaction; and not completing the study year. The great majority of the survivors with impaired wellbeing at wave 2 also reported impaired performance, $n=57$ (88\%). Furthermore, survivors who reported impaired performance and wellbeing were less likely to be satisfied with the school's support measures.

Supplementary material Appendix 1 presents descriptive data separately for survivors who reported both impaired wellbeing and achievements, and those who reported impaired performance only or impaired wellbeing only. These descriptive characteristics indicate that the symptom levels were particularly high among survivors with both perceived impaired performance and impaired wellbeing, whereas the symptom levels of those who reported impaired performance only, were more similar to those with unchanged and/or improved performance or wellbeing. To test if there was a non-linear relationship between exposure and impaired school functioning; e.g., that only the most severely exposed survivors would have impaired school 
Table 2 Characteristics of survivors of the Utøya attack by impaired school performance and impaired wellbeing assessed at wave 2, 14-15 months after the attack

\begin{tabular}{|c|c|c|c|c|c|c|}
\hline \multirow[t]{4}{*}{ Characteristics } & \multicolumn{6}{|c|}{ School functioning year after attack } \\
\hline & \multicolumn{2}{|c|}{ Impaired performance $(n=233)$} & \multirow[t]{3}{*}{$p$ value } & \multicolumn{2}{|c|}{ Impaired wellbeing $(n=231)$} & \multirow[t]{3}{*}{$p$ value } \\
\hline & Yes $(n=143)$ & No $(n=90)$ & & Yes $(n=66)$ & No $(n=165)$ & \\
\hline & $n /$ mean $(\% / s d)$ & $n /$ mean $(\% / s d)$ & & $n /$ mean $(\% / s d)$ & $n /$ mean $(\% / s d)$ & \\
\hline Mean age at attack $(n=233)$ & $18.45(2.78)$ & $18.10(2.10)$ & 0.299 & $18.20(2.88)$ & $18.31(2.39)$ & 0.768 \\
\hline Female gender $(n=233)$ & $75(52)$ & $35(39)$ & 0.044 & $36(55)$ & $72(44)$ & 0.133 \\
\hline Non-Norwegian origin $(n=229)$ & $14(10)$ & $5(6)$ & 0.274 & $10(15)$ & $9(6)$ & 0.016 \\
\hline Financially disadvantaged $(n=229)$ & $32(23)$ & $14(16)$ & 0.168 & $20(31)$ & $25(15)$ & 0.007 \\
\hline Admitted to hospital after attack $(n=233)$ & $11(8)$ & $6(7)$ & 0.769 & $5(8)$ & $12(7)$ & 0.936 \\
\hline Predisaster MHS utilization $(n=234)$ & $35(25)$ & $22(25)$ & 0.986 & $19(29)$ & $38(23)$ & 0.352 \\
\hline \multicolumn{7}{|l|}{ Sleep problems } \\
\hline Wave $1(n=208)$ & $63(50)$ & $16(20)$ & $<0.001$ & $34(61)$ & $43(29)$ & $<0.001$ \\
\hline Wave $2(n=231)$ & $43(30)$ & $12(14)$ & 0.004 & $23(35)$ & $30(18)$ & 0.008 \\
\hline \multicolumn{7}{|l|}{ Impaired performance after $4-5$ months } \\
\hline Wave $1(n=193)$ & $100(86)$ & $34(44)$ & $<0.001$ & $47(92)$ & $86(61)$ & $<0.001$ \\
\hline \multicolumn{7}{|l|}{ Impaired wellbeing after $4-5$ months } \\
\hline Wave $1(n=192)$ & $44(39)$ & $13(17)$ & 0.001 & $33(65)$ & $24(17)$ & $<0.001$ \\
\hline Received auxiliary school support $(n=230)$ & $100(73)$ & $48(53)$ & 0.002 & $49(78)$ & $100(61)$ & 0.019 \\
\hline \multicolumn{7}{|l|}{ Satisfied with study support $(n=197)$} \\
\hline No/little & $26(22)$ & $8(11)$ & 0.047 & $17(32)$ & $17(13)$ & 0.001 \\
\hline Somewhat & $28(23)$ & $11(16)$ & & $15(28)$ & $23(17)$ & \\
\hline Much/very much & $66(55)$ & $51(73)$ & & $22(41)$ & $94(70)$ & \\
\hline Did not complete study year $(n=229)$ & $50(36)$ & $9(10)$ & $<0.001$ & $28(43)$ & $30(19)$ & $<0.001$ \\
\hline Mean exposure $(0-13)(n=229)$ & $8.37(2.30)$ & $8.20(2.17)$ & 0.584 & $8.92(2.13)$ & $8.10(2.26)$ & 0.013 \\
\hline \multicolumn{7}{|l|}{ Posttraumatic stress reactions (mean PTSD-RI) } \\
\hline Wave $1(n=209)$ & $1.65(0.71)$ & $1.28(0.68)$ & $<0.001$ & $1.95(0.68)$ & $1.34(0.67)$ & $<0.001$ \\
\hline Wave $2(n=233)$ & $1.32(0.64)$ & $1.04(0.64)$ & 0.001 & $1.66(0.63)$ & $1.03(0.58)$ & $<0.001$ \\
\hline \multicolumn{7}{|l|}{ Symptoms of anxiety/depression (mean HSCL-8) } \\
\hline Wave $1(n=209)$ & $2.16(0.64)$ & $1.79(0.57)$ & $<0.001$ & $2.44(0.60)$ & $1.86(0.58)$ & $<0.001$ \\
\hline Wave $2(n=233)$ & $1.86(0.63)$ & $1.59(0.57)$ & 0.001 & $2.19(0.68)$ & $1.59(0.46)$ & $<0.001$ \\
\hline \multicolumn{7}{|l|}{ Somatic symptoms (mean CSSI-8) } \\
\hline Wave $1(n=209)$ & $1.81(0.56)$ & $1.54(0.45)$ & $<0.001$ & $1.97(0.62)$ & $1.59(0.46)$ & $<0.001$ \\
\hline Wave $2(n=233)$ & $1.68(0.48)$ & $1.50(0.45)$ & 0.005 & $1.84(0.54)$ & $1.51(0.41)$ & $<0.001$ \\
\hline \multicolumn{7}{|l|}{ Social support (mean FSSQ-7) } \\
\hline Wave $1(n=209)$ & $4.51(0.61)$ & $4.62(0.52)$ & 0.182 & $4.37(0.70)$ & $4.63(0.51)$ & 0.014 \\
\hline Wave $2(n=233)$ & $4.55(0.60)$ & $4.57(0.61)$ & 0.819 & $4.36(0.72)$ & $4.62(0.55)$ & 0.009 \\
\hline \multicolumn{7}{|l|}{ Life satisfaction (mean $0-10$ ) } \\
\hline Wave $2(n=231)$ & $6.94(1.98)$ & $7.84(1.75)$ & 0.001 & $6.15(2.06)$ & $7.75(1.70)$ & $<0.001$ \\
\hline
\end{tabular}

functioning, we examined academic performance and school wellbeing according to four exposure categories based on the exposure scores for the 25th-, 50th-, and 75th-percentiles for our sample. However, impaired academic performance and impaired wellbeing at school were quite common also in survivors with exposure scores in the lower range of the scale (Supplementary material Appendix 2)

Table 3 displays study characteristics by MHS utilization. Compared to non-users, survivors who had used MHS were more likely to report either impaired or improved academic performance and school wellbeing. They were also more likely to have received auxiliary school support and to have needed practical facilitations. MHS utilization in the period 5-15 months after the attack (wave 2) was additionally associated with perceived needs for auxiliary academic assistance from teachers and additional social or emotional support. There were no significant differences with respect to satisfaction with the school support 
Table 3 Study characteristics for youth survivors the year following the terror attack according to mental health service (MHS) utilization approximately $0-5$ months (wave 1) and 5-15 months (wave 2) after the attack

\begin{tabular}{|c|c|c|c|c|c|c|}
\hline \multirow[t]{3}{*}{ Characteristics } & \multicolumn{2}{|c|}{$\begin{array}{l}\text { MHS utilization wave } 1 \\
(n=207)\end{array}$} & \multirow[t]{3}{*}{$p$ value } & \multicolumn{2}{|c|}{$\begin{array}{l}\text { MHS utilization wave } 2 \\
(n=233)\end{array}$} & \multirow[t]{3}{*}{$p$ value } \\
\hline & Yes $(n=146)$ & No $(n=61)$ & & Yes $(n=157)$ & No $(n=76)$ & \\
\hline & $n(\%)$ & $n(\%)$ & & $n(\%)$ & $n(\%)$ & \\
\hline \multicolumn{7}{|c|}{ Academic performance $(n=233)$} \\
\hline Impaired & $93(65)$ & $31(51)$ & \multirow[t]{3}{*}{0.022} & $108(70)$ & $32(43)$ & \multirow[t]{3}{*}{$<0.001$} \\
\hline Unchanged & $30(21)$ & $24(39)$ & & $26(17)$ & $35(47)$ & \\
\hline Improved & $21(15)$ & $6(10)$ & & $20(13)$ & $8(11)$ & \\
\hline \multicolumn{7}{|c|}{ School wellbeing $(n=231)$} \\
\hline Impaired & $46(33)$ & $10(16)$ & \multirow[t]{3}{*}{0.005} & $52(34)$ & $13(18)$ & \multirow[t]{3}{*}{0.01} \\
\hline Unchanged & $62(44)$ & $42(69)$ & & $66(43)$ & $47(64)$ & \\
\hline Improved & $33(23)$ & $9(15)$ & & $35(23)$ & $14(19)$ & \\
\hline \multirow{2}{*}{\multicolumn{7}{|c|}{$\begin{array}{l}\text { Needed auxiliary school support } \\
\text { (a) Practical support }(n=225)\end{array}$}} \\
\hline & & & & & & \\
\hline No/little & $41(30)$ & $29(48)$ & \multirow[t]{3}{*}{0.041} & $34(23)$ & $45(61)$ & \multirow[t]{3}{*}{$<0.001$} \\
\hline Some & $31(22)$ & $12(20)$ & & $35(24)$ & $15(20)$ & \\
\hline Much/very much & $67(48)$ & $20(33)$ & & $78(53)$ & $14(19)$ & \\
\hline \multicolumn{7}{|c|}{ (b) Academic support $(n=223)$} \\
\hline No/little & $64(47)$ & $35(57)$ & \multirow[t]{3}{*}{0.208} & $59(41)$ & $52(70)$ & \multirow[t]{3}{*}{$<0.001$} \\
\hline Some & $27(20)$ & $13(21)$ & & $36(25)$ & $10(14)$ & \\
\hline Much/very much & $46(34)$ & $13(21)$ & & $50(34)$ & $12(16)$ & \\
\hline \multicolumn{7}{|c|}{ (c) Social/emotional support $(n=222)$} \\
\hline No/little & $84(62)$ & $45(74)$ & \multirow[t]{3}{*}{0.249} & $83(58)$ & $62(84)$ & \multirow[t]{3}{*}{$<0.001$} \\
\hline Some & $30(22)$ & $10(16)$ & & $37(26)$ & $9(12)$ & \\
\hline Much/very much & $22(16)$ & $6(10)$ & & $24(17)$ & $3(4)$ & \\
\hline \multicolumn{7}{|c|}{ Received auxiliary school support $(n=230)$} \\
\hline Yes & $96(68)$ & $32(53)$ & \multirow[t]{2}{*}{0.034} & $113(74)$ & $34(46)$ & \multirow[t]{2}{*}{$<0.001$} \\
\hline No & $45(32)$ & $29(48)$ & & $39(26)$ & $40(54)$ & \\
\hline \multicolumn{7}{|c|}{ Satisfied with school support $(n=191)$} \\
\hline No/little & $25(21)$ & $5(11)$ & \multirow[t]{3}{*}{0.270} & $27(21)$ & $6(11)$ & \multirow[t]{3}{*}{0.264} \\
\hline Some & $23(19)$ & $12(26)$ & & $26(20)$ & $13(23)$ & \\
\hline Much/very much & $73(60)$ & $29(63)$ & & $78(60)$ & $37(66)$ & \\
\hline \multicolumn{7}{|c|}{ Completed study year $(n=231)$} \\
\hline No & $39(27)$ & $12(20)$ & \multirow[t]{2}{*}{0.276} & $44(29)$ & $14(19)$ & \multirow[t]{2}{*}{0.130} \\
\hline Yes & $104(73)$ & $48(80)$ & & $110(72)$ & $59(81)$ & \\
\hline
\end{tabular}

or completing the study year according to MHS utilization. In multivariate logistic regression analyses, higher age and posttraumatic stress reactions were associated with perceived impaired academic performance after additional adjustments for gender, somatic symptoms and social support (Table 4). When additionally adjusting for impaired school wellbeing (yes/no), age and impaired wellbeing were associated with impaired performance, but not posttraumatic stress reactions. With respect to impaired school wellbeing, only posttraumatic stress reactions remained associated with impaired wellbeing after similar adjustments. This association remained significant when additionally adjusting for impaired academic performance. In the post hoc analysis, non-Norwegian origin and being financially disadvantaged no longer remained significantly associated with impaired school wellbeing after adjusting for posttraumatic stress reactions, age and gender.

\section{Discussion}

In the year following the terrorist attack, the majority of survivors perceived that their academic performance had worsened, with more than one in four reporting impaired school wellbeing. Furthermore, they declared substantial needs for school support. Our findings are in accordance with a recent register-based study of a smaller student sample of survivors from the Utøya attack, which displayed that their grades declined and their absence increased the year after the event [2]. 


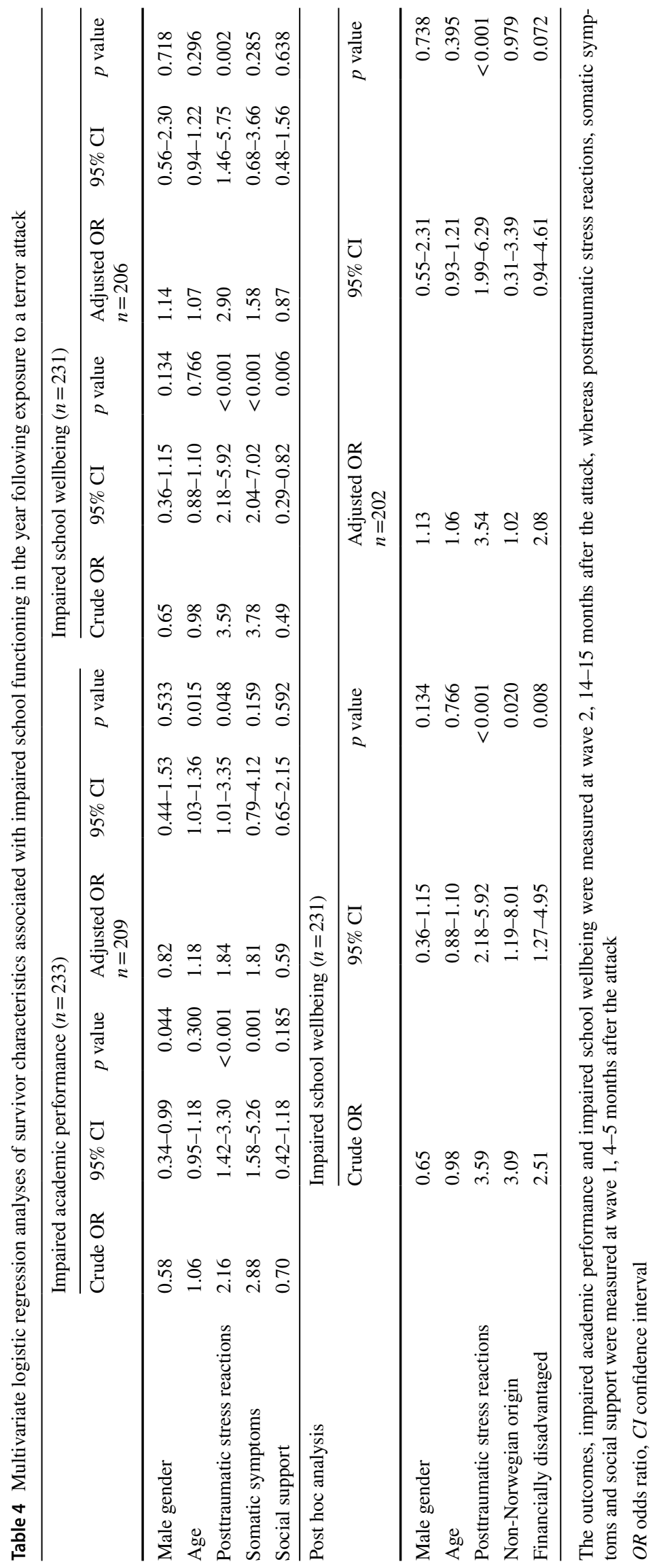


Both impaired academic performance and impaired school wellbeing were associated with higher levels of mental and physical health problems, and lower life quality (Table 2). Most survivors with impaired wellbeing also reported impaired academic performance. Our findings suggest that survivors with impaired wellbeing at school the year following the attack were particularly at risk for poorer health and lower life quality (Appendix 1). Those who thrived less, reported significantly less social support. Furthermore, those who reported impaired academic performance and/or poorer school wellbeing were more likely to be less satisfied with the support they had received from their respective school/educational institutions. This relationship highlights the importance of promoting a supportive school environment in the aftermath of mass trauma. Prior research from war and disaster settings has demonstrated that school and teacher-based interventions could play a major role to promote children's preparedness and resilience for coping with traumatic events, as well as to recover and regain normal routine $[24,25]$. Survivors with poorer school performance and/or wellbeing were more likely to report higher levels of posttraumatic stress, symptoms of anxiety and depression and somatic symptoms both early in the study year (wave 1) and after the end of the year (wave 2). A recent meta-analysis documented that posttraumatic stress disorder had a particularly adverse impact on attention, verbal memory, and speed of information processing, which are all important for learning capacities [26]. Symptoms of posttraumatic stress, anxiety and depression as well as pain and other somatic symptoms can trouble concentration, sleep, and cognitive functioning. They may consequently adversely affect the academic performance and cause absence from school/studies. On the other hand, poorer achievements and impaired wellbeing at school may possibly also maintain, aggravate or generate psychological distress and/or psychosomatic ailments.

Survivors who disclosed impaired school functioningboth with respect to academic performance and wellbeingwere clearly more likely to report sleep problems both early in the school/study year (wave 1, 4-5 months after the attack) and after the first school year following the attack (wave 2, 14-15 months after the attack). Evaluation of sleep quality in a school/study setting may therefore be valuable to identify trauma-exposed youth at risk of impaired educational functioning and health adversity. With respect to sociodemographic factors, female survivors were more likely than male survivors to perceive their academic performance as impaired the year following the attack. Moreover, impaired wellbeing was more common in survivors who were financially disadvantaged and of non-Norwegian origin. However, after multivariate adjustments, the associations with sociodemographic variables no longer remained significant (Table 4). Whereas $29 \%$ of the survivors disclosed impaired wellbeing, $21 \%$ actually reported improved wellbeing at school/studies the year following the attack. We do not have data on why their wellbeing improved, but it is possible that they received both more formal and informal support at school/studies following the attack.

Those who used MHS were more likely to attain less and need more support at school than non-users. This could be expected due to higher levels of psychopathology in survivors who receive MHS [27].

Still, there were no significant differences with respect to satisfaction with support measures or self-reported completion of the study year by MHS utilization. This might indicate that MHS utilization facilitated access to support measures that could have helped survivors to function at school/studies despite posttraumatic stress reactions. An important question for future follow-up is how educational institutions and mental health professionals should work together to support youth in the wake of terrorist attacks and other mass trauma.

The close relationship between poor health, lower life quality and impaired school functioning underscores the importance of cooperation among school personnel and healthcare providers [28]. Our study indicates that assessment of school functioning is important to identify young survivors with a need for follow-up from school personnel and health care providers. Mental health professionals typically come into contact with trauma-exposed individuals through referral. Yet a major challenge in post-disaster outreach is to identify individuals in need of treatment. Indeed, prior research has uncovered high unmet needs in the aftermath of terrorist attacks $[29,30]$. Teachers, school nurses and other educational staff may play a primordial role in primary prevention of post-trauma adversity and the identification of youth in need of treatment. The majority of the survivors reported impaired academic performance both at 4-5 months (69\%) and 14-15 months (61\%) after the attack. Hence, schools should evaluate the academic performance and organize educational support measures to prevent and/or improve impaired academic performance in trauma-exposed students. Although less prevalent, an important minority reported impaired school wellbeing at 4-5 months (30\%) and 14-15 months (29\%) after the attack. Such impairment in wellbeing was strongly associated with higher risk of mental health problems, lower life quality, and sleep problems. An important measure to strengthen the outreach to trauma-exposed youth may be to educate teachers about common posttraumatic stress reactions and behavioral changes they may observe after traumatic events. Furthermore, about how, when and to whom they should refer students in need of support measures. This study indicates that an assessment of impaired wellbeing at school and sleep problems, may be valuable for teachers and educational staff to identify students for referral to MHS. 
There is a possibility of a bidirectional relationship between school functioning and mental health problems. Stress reactions may impair sleep, concentration and cognition, which may adversely impact school functioning. On the other hand, poorer academic performance and wellbeing at school and studies might also be psychologically burdensome and potentially maintain or worsen mental health problems. Early interventions might prevent the development of a vicious circle of accelerating mental health and educational problems. The school community may play a pivotal part in children's and adolescents' trauma recovery by promoting a supportive environment and a sense of belonging. School activities and routines may contribute to restore a feeling of normality and social equilibrium. Conversely, a lack of support, deterioration of academic achievement and negative reactions at school may prevent healing after trauma.

\section{Strengths and limitations}

This study provides new knowledge on long-term school functioning and its relationship to health in young survivors of a terrorist attack. It provides new insight into the impact of single event trauma, whereas previous research primarily has addressed educational consequences of chronic forms of trauma through a cross-sectional assessment. Furthermore, all survivors in our study population were exposed to lifethreatening events which have been identified. The relatively homogenous trauma exposure may have reduced the risk of confounding, and the clearly defined study population may have diminished the risk of selection bias. There were also several study limitations. Our study relied on self-reports, which may be inaccurate. Besides, we did not have comparison data from unexposed students in the general population. Moreover, the survivors went to different schools across geographical regions and levels; including lower and upper secondary schools, and higher education institutions. We lacked detailed data about how the respective schools supported survivors, and whether it differed between schools. Norway has a universal healthcare coverage, and public education is free of charge. Findings may not be directly generalizable to countries with a different organization of health services and education system. Future studies should explore in more depth the academic performance and wellbeing at school after exposure to traumatic events. The youths' self-reports should be combined with objective data on school grades and absence, as well as reports from their teachers and parents with respect to their perception of how the youth cope and function following the traumatic event. Furthermore, a qualitative assessment may provide valuable insight into how the youth conceptualize wellbeing, and which factors that impact their wellbeing at school. There is also a need for research on the efficiency and efficacy of different types of school interventions in the aftermath of terrorist attacks and other mass trauma.

\section{Conclusion}

A terrorist attack can have a considerable negative impact on young survivors' academic performance and school wellbeing, which are further associated with poorer health. It is therefore essential to provide appropriate school support, and to coordinate the delivery of health care with proper follow-up at school.

Acknowledgements We sincerely thank all participants. Our study was funded by the Norwegian Directorate of Health and the Norwegian Ministry of Education and Research.

\section{Compliance with ethical standards}

Conflict of interest On behalf of all authors, the corresponding author states that there is no conflict of interest.

Ethical standards The study was approved by the Regional Committees for Medical and Health Research Ethics South East and North and performed in accordance with the ethical standards in the 1964 Declaration of Helsinki and its later amendments. The study participation was based on written informed consent. Parental consent was required for survivors younger than 16 years of age, as stipulated by Norwegian laws.

Open Access This article is distributed under the terms of the Creative Commons Attribution 4.0 International License (http://creativeco mmons.org/licenses/by/4.0/), which permits unrestricted use, distribution, and reproduction in any medium, provided you give appropriate credit to the original author(s) and the source, provide a link to the Creative Commons license, and indicate if changes were made.

\section{References}

1. Strom IF, Thoresen S, Wentzel-Larsen T, Hjemdal OK, Lien L, Dyb G (2013) Exposure to life adversity in high school and later work participation: a longitudinal population-based study. J Adolesc 36(6):1143-1151

2. Strom IF, Schultz JH, Wentzel-Larsen T, Dyb G (2016) School performance after experiencing trauma: a longitudinal study of school functioning in survivors of the Utoya shootings in 2011. Eur J Psychotraumatol 7:31359

3. Hafstad GS, Dyb G, Jensen TK, Steinberg AM, Pynoos RS (2014) PTSD prevalence and symptom structure of DSM-5 criteria in adolescents and young adults surviving the 2011 shooting in Norway. J Affect Disord 169:40-46

4. American Psychiatric Association (2013) Diagnostic and statistical manual of mental disorders (DSM-5), 5th edn. American Psychiatric Association, Washington, DC

5. Pat Horenczyk R, Abramovitz R, Peled O, Brom D, Daie A, Chemtob C (2007) Adolescent exposure to recurrent terrorism 
in Israel: posttraumatic distress and functional impairment. Am J Orthopsychiatry 77(1):76-85

6. De Bellis M, Kuchibhatla M (2006) Cerebellar volumes in pediatric maltreatment-related posttraumatic stress disorder. Biol Psychiatry 60(7):697-703

7. Saigh P, Yasik A, Oberfield R, Halamandaris P, Bremner JD (2006) The intellectual performance of traumatized children and adolescents with or without posttraumatic stress disorder. J Abnorm Psychol 115(2):332-340

8. Scrimin S, Moscardino U, Capello F, Axia G (2009) Attention and memory in school-age children surviving the terrorist attack in Beslan, Russia. J Clin Child Adolesc Psychol 38(3):402-414

9. Afari N, Ahumada SM, Wright LJ, Mostoufi S, Golnari G, Reis V, Cuneo JG (2014) Psychological trauma and functional somatic syndromes: a systematic review and meta-analysis. Psychosom Med 76(1):2-11

10. Ozer EJ, Best SR, Lipsey TL, Weiss DS (2003) Predictors of posttraumatic stress disorder and symptoms in adults: a meta-analysis. Psychol Bull 129(1):52-73

11. Brewin CR, Holmes EA (2003) Psychological theories of posttraumatic stress disorder. Clin Psychol Rev 23(3):339-376

12. Shonkoff JP, Garner AS, Committee on Psychosocial Aspects of C, Family H, Committee on Early Childhood A, Dependent C, Section on D, Behavioral P (2012) The lifelong effects of early childhood adversity and toxic stress. Pediatrics 129(1):e232-e246

13. Fu C, Underwood C (2015) A meta-review of school-based disaster interventions for child and adolescent survivors. J Child Adolesc Ment Health 27(3):161-171

14. The Norwegian Ministry of Education (2011) Håndtering av tragedien på Utøya og i Oslo den 22. juli 2011 ved skolestart. Ref. nr. 201103688. In

15. The Norwegian Ministry of Education (2012) Til lærere, skoleledere og skoleeiere - om tilrettelegging av skolehverdagen ogeksamensgjennomføringen for berørte elever etter 22. juli. Ref. nr. 201104481

16. Rokholt EG, Schultz JH, Langballe A (2016) Negotiating a new day: parents' contributions to supporting students' school functioning after exposure to trauma. Psychol Res Behav Manag 9:81-93

17. Stene LE, Dyb G (2016) Research participation after terrorism: an open cohort study of survivors and parents after the 2011 Utoya attack in Norway. BMC Res Notes 9(1):57

18. Pynoos RS, Rodriguez N, Steinberg AM, Stuber M, Frederick C (1998) UCLA ptsd index for DSM-IV. University of California

19. Derogatis LR, Lipman RS, Rickels K, Uhlenhuth EH, Covi L (1974) The Hopkins Symptom Checklist (HSCL): a self-report symptom inventory. Behav Sci 19(1):1-15
20. Strand BH, Dalgard OS, Tambs K, Rognerud M (2003) Measuring the mental health status of the Norwegian population: a comparison of the instruments SCL-25, SCL-10, SCL-5 and MHI-5 (SF-36). Nord J Psychiatry 57(2):113-118

21. Walker LS, Beck JE, Garber J, Lambert W (2008) Children's somatization inventory: psychometric properties of the revised form (CSI-24). J Pediatr Psychol 34(4):430-440

22. Broadhead WE, Gehlbach SH, de Gruy FV, Kaplan BH (1988) The Duke-UNC Functional Social Support Questionnaire. Measurement of social support in family medicine patients. Med Care 26:709-723

23. Dyb G, Jensen TK, Nygaard E, Ekeberg Ø, Diseth TH, WentzelLarsen T, Thoresen S (2013) Post-traumatic stress reactions in survivors of the 2011 massacre on Utøya Island, Norway. Br J Psychiatry J Ment Sci 204(5):361-367. https://doi.org/10.1192/ bjp.bp.113.133157

24. Wolmer L, Hamiel D, Laor N (2011) Preventing children's posttraumatic stress after disaster with teacher-based intervention: a controlled study. J Am Acad Child Adolesc Psychiatry 50(4):340 348 (348 e341-342)

25. Wolmer L, Hamiel D, Barchas JD, Slone M, Laor N (2011) Teacher-delivered resilience-focused intervention in schools with traumatized children following the second Lebanon war. J Trauma Stress 24(3):309-316

26. Scott JC, Matt GE, Wrocklage KM, Crnich C, Jordan J, Southwick SM, Krystal JH, Schweinsburg BC (2015) A quantitative metaanalysis of neurocognitive functioning in posttraumatic stress disorder. Psychol Bull 141(1):105-140

27. Stene LE, Dyb G (2015) Health service utilization after terrorism: a longitudinal study of survivors of the 2011 Utoya attack in Norway. BMC Health Serv Res 15:158

28. Adelman HS, Taylor L (2006) Mental health in schools and public health. Public Health Rep 121(3):294-298

29. Fairbrother G, Stuber J, Galea S, Pfefferbaum B, Fleischman AR (2004) Unmet need for counseling services by children in New York City after the September 11th attacks on the World Trade Center: implications for pediatricians. Pediatrics 113(5):1367-1374

30. Pfefferbaum B, Sconzo GM, Flynn BW, Kearns LJ, Doughty DE, Gurwitch RH, Nixon SJ, Nawaz S (2003) Case finding and mental health services for children in the aftermath of the Oklahoma City bombing. J Behav Health Serv Res 30(2):215-227 